\title{
Geopotential field anomalies and regional tectonic features - two case studies: southern Africa and Germany
}

\author{
Monika Korte $^{1}$ and Mioara Mandea ${ }^{2}$ \\ ${ }^{1}$ German Research Centre for Geosciences GFZ, Telegrafenberg, 14473 Potsdam, Germany \\ ${ }^{2}$ Centre National D'Etudes Spatiales 2, Place Maurice Quentin, 75001 Paris, France \\ Correspondence to: Monika Korte (monika@gfz-potsdam.de)
}

Received: 16 December 2015 - Published in Solid Earth Discuss.: 20 January 2016

Revised: 8 April 2016 - Accepted: 11 April 2016 - Published: 9 May 2016

\begin{abstract}
Maps of magnetic and gravity field anomalies provide information about physical properties of the Earth's crust and upper mantle, helpful in understanding geological conditions and tectonic structures. Depending on data availability, whether from the ground, airborne, or from satellites, potential field anomaly maps contain information on different ranges of spatial wavelengths, roughly corresponding to sources at different depths. Focussing on magnetic data, we compare amplitudes and characteristics of anomalies from maps based on various available data and as measured at geomagnetic repeat stations. Two cases are investigated: southern Africa, characterized by geologically old cratons and strong magnetic anomalies, and the smaller region of Germany with much younger crust and weaker anomalies. Estimating lithospheric magnetic anomaly values from the ground stations' time series (repeat station crustal biases) reveals magnetospheric field contributions causing time-varying offsets of several $\mathrm{nT}$ in the results. Similar influences might be one source of discrepancy when merging anomaly maps from different epochs. Moreover, we take advantage of recently developed satellite potential field models and compare magnetic and gravity gradient anomalies of $\sim 200 \mathrm{~km}$ resolution. Density and magnetization represent independent rock properties and thus provide complementary information on compositional and structural changes. Comparing short- and long-wavelength anomalies and the correlation of rather large-scale magnetic and gravity anomalies, and relating them to known lithospheric structures, we generally find a better agreement in the southern African region than the German region. This probably indicates stronger concordance between near-surface (down to at most a few $\mathrm{km}$ ) and deeper (several kilometres down to Curie depth)
\end{abstract}

structures in the former area, which can be seen to agree with a thicker lithosphere and a lower heat flux reported in the literature for the southern African region.

\section{Introduction}

Geopotential field anomalies are the spatial magnetic and gravity field variations depending on surface geology, tectonics, changes in composition, physical properties, and thickness of the crust and upper mantle. Anomaly maps are used to constrain structures of the lithosphere, as variations in magnetization and density give useful information for understanding geological conditions and tectonic processes. Generally, anomaly maps based on ground, marine, and airborne surveys cover areas in the order of kilometres to tens of kilometres with a dense grid of measurements, providing detailed information on locally limited structures originating mostly close to the Earth's surface. However, geological and tectonic structures, in particular including deeper lithospheric ones, can have dimensions up to hundreds or even thousands of kilometres and extend down to the so-called Curie depth at around 10 to several tens of kilometres below Earth's surface (Rajaram, 2007). At this depth temperature becomes too high to allow for the existence of permanent magnetization.

Magnetic anomaly maps obtained from satellite data provide a long-wavelength picture associated with such structures (e.g. Regan et al., 1975; Ravat et al., 1992, 1993). Recent examples are, e.g. the MF6 and MF7 models ${ }^{1}$ (Maus et al., 2008) based on CHAMP ${ }^{2}$ magnetic satellite data,

\footnotetext{
${ }^{1}$ http://www.geomag.org/models/

${ }^{2}$ http://op.gfz-potsdam.de/champ/
} 
which resolve the magnetic signatures for spatial wavelengths from $2700 \mathrm{~km}$ down to about $200 \mathrm{~km}$. This range is constrained by the magnetic core field for the long wavelengths and the satellite's minimum altitude for the short ones. The study of intermediate-wavelength anomalies requires a combination of satellite, airborne, and/or ground measurements, as e.g. applied on the global scale for the World Digital Magnetic Anomaly Map (WDMAM) (Korhonen et al., 2007; Dyment et al., 2015) and on regional scale for some countries by revised spherical cap magnetic field modelling (R-SCHA) (Thébault et al., 2006; Korte and Thébault, 2007; Vervelidou, 2013).

In geomagnetism, high-resolution data and maps usually represent scalar magnetic anomalies (see, e.g. Blakely, 1996; Hamoudi et al., 2011), while recent satellite missions provide large-scale vector lithospheric field maps (see, e.g. Olsen and Kotsiaros, 2011). The R-SCHA models attempt to provide detailed vector anomaly information by combining largescale satellite vector anomaly information and detailed aeromagnetic scalar results complemented by point-wise ground vector anomaly information obtained from magnetic repeat station surveys.

Repeat stations are well-defined locations where magnetic absolute vector observations are carried out for one to a few days once a year to every couple of years. They are mainly used to map the core (main) magnetic field and its secular variation on a regional scale (e.g. Newitt et al., 1996; Barraclough and De Santis, 2011). The measurements of three magnetic components (generally declination, inclination, and intensity) are processed to represent the internal field. Robust estimates of the localized vector anomaly values at their locations, also known as repeat station crustal biases, can be obtained when time series over several years are available. To express the vector magnetic anomalies the $X$ (northward), $Y$ (eastward), $Z$ (downward), and $F$ (total intensity) components are used.

The use of repeat station vector information clearly modifies the vector anomaly description of the regional model at low altitudes, but Korte and Thébault (2007) note that a compatibility limit exists between the information provided by the repeat station vectors and the aeromagnetic scalar data. Korte and Thébault (2007) indicate that a definitive reason for this discrepancy is difficult to attain, i.e. whether it is due to insufficient resolution of the model, problems with levelling and/or positioning of the airborne data, or uncertainties in the repeat station lithospheric field data.

Based on new repeat station results with improved external field correction, recently produced scalar anomaly maps, and regional as well as global vector magnetic anomaly models, we investigate the agreement between robust localized estimates of magnetic scalar and vector anomalies and available maps. Furthermore, we study links between different short- and long-wavelength anomaly representations. Taking advantage of recent new satellite geopotential field information, we complement our study by a combination of the large- scale ( $\sim 200 \mathrm{~km}$ resolution) magnetic anomalies with gravity gradient information of a comparable scale to discuss their links to specific lithospheric structures like terrane boundaries and faults.

We focus on two regions: southern Africa (encompassing South Africa, Namibia and Botswana) and Germany (with surrounding areas when using satellite results). This choice is motivated twofold. Firstly, we take advantage of our intimate knowledge of the repeat station data from these two regions. Secondly, these regions represent rather diverse geological and geophysical conditions: old Archean crust with strong magnetic anomalies for southern Africa, and much younger, weakly magnetized crust in central Europe. Moreover, the two areas have rather different sizes of dominant tectonic units.

This paper is organized as follows. The repeat station data, magnetic anomaly maps, vector anomaly magnetic and gravity gradient models are described in the next section. Thereafter, we discuss the information contained in maps of different minimum wavelengths, and we compare the ground data to available maps and models. Finally, we discuss implications for geological and tectonic interpretation of magnetic and gravity anomalies before concluding.

\section{Data}

\subsection{Geomagnetic repeat station data}

Any geomagnetic field observation combines signals from the core field generated by the geodynamo, the lithospheric field, and also more rapidly varying magnetic signatures of electric current systems in ionosphere and magnetosphere and their induced counterparts. Different techniques are commonly applied to minimize the undesired contributions in different data products, in order to obtain a signal which is able to characterize the magnetic source one is interested in (core, lithosphere, external fields) as best as possible. All the data we use in the following are processed data products.

Commonly, in repeat station data processing, the recordings from a nearby variometer or nearest geomagnetic observatory are used to eliminate the short-period external field variations, up to half a year or longer, when the data are reduced to annual means (Newitt et al., 1996; Barraclough and De Santis, 2011). Lithospheric field estimates at each repeat station can be obtained by subtraction of a core field spherical harmonic field model. The lithospheric field can be assumed to be constant over at least several years, as signals from changes in induced magnetic anomalies are in the noise level on these timescales (Korte and Haak, 2000; Thébault et al., 2009). Here, we use the GRIMM3 model (Lesur et al., 2010; Mandea et al., 2012) up to a spherical harmonic degree and order 14 to describe the core field contribution. This model also includes an estimate of the large-scale magnetospheric field. The long-period variation of this contribution is 
not considered in the standard repeat station data processing. As demonstrated by Korte (2015) the estimation of magnetospheric field by the GRIMM3 model agrees well with the signal observed in observatory annual means. The following examples demonstrate that taking into account the magnetospheric contribution improves the description of the lithospheric anomalies, assumed to be constant, based on repeat station measurements.

\subsubsection{Southern African region}

Since 2005, repeat station measurements have been carried out annually at 40 locations in South Africa, Botswana, and Namibia. Distances between the stations lie in the order of 200 to $400 \mathrm{~km}$. The observations are carried out late in the evening and early in the morning. They are reduced to the night-time averages by using a continuously recording variometer set up nearby (see Korte et al., 2007, for details). To obtain two sets of local crustal field estimates, we subtract the GRIMM3 core field model prediction for that night and the average of hourly GRIMM3 core and magnetospheric field predictions over the same time interval of measurements, respectively. Due to the time span covered by the model only values measured between 2005.0 and 2010.0 are used.

All residual time series have been checked and very few obvious outliers were removed. The average of the remaining values (between two and five, often four) provides robust estimates of the lithospheric field contribution at the repeat station location. Three of the 40 stations show strongly diverging residuals with very few observations and they have been omitted from this study. Individual results with their standard deviations are listed in supplementary Tables S1 and S2. The average standard deviations lie between $2.9 \mathrm{nT}$ in $Z$ and $10.2 \mathrm{nT}$ in $X$ when only the core field is removed. These values clearly become smaller in all components if the magnetospheric field contribution is additionally considered (see Table 1).

Figure 1 shows how the scatter reduces for the individual stations by considering the magnetospheric field contribution. The reduction is strongest in the $X$ component, while for the other components, in some cases the effect is smaller and in a few cases the scatter even increases. This is most likely due to uncertainties in the repeat station results, but might also reflect an insufficient description of the external field by the model at certain times and locations. Lithospheric anomaly values for the three geomagnetic observatories Hermanus (HER), Hartebeesthoek (HBK), and Tsumeb (TSU) are obtained from their annual mean values from 2001.5 to 2009.5. The scatter of their residuals around the estimated lithospheric anomaly values are shown in Fig. 2a. This figure clearly points out the systematic nature of the magnetospheric signal and the improvement leading to more constant estimated anomaly values when considering this effect. Moreover, as a weak magnetospheric influence is present even at magnetically quiet times we find offsets in the av-
Table 1. Average standard deviation $\sigma$ in lithospheric anomaly estimation at repeat station locations.

\begin{tabular}{|c|c|c|c|c|}
\hline & $\sigma X(\mathrm{nT})$ & $\sigma Y(\mathrm{nT})$ & $\sigma Z(\mathrm{nT})$ & $\sigma F(\mathrm{nT})$ \\
\hline \multicolumn{5}{|c|}{ Southern Africa } \\
\hline (a) & 10.2 & 3.9 & 2.9 & 3.1 \\
\hline (b) & 4.0 & 3.5 & 2.4 & 2.6 \\
\hline \multicolumn{5}{|c|}{ Germany } \\
\hline (a) & 6.4 & 3.1 & 6.4 & 3.6 \\
\hline (b) & 1.3 & 2.0 & 2.7 & 2.5 \\
\hline
\end{tabular}

(a) Core field subtracted only; (b) Core and large-scale magnetospheric field subtracted.

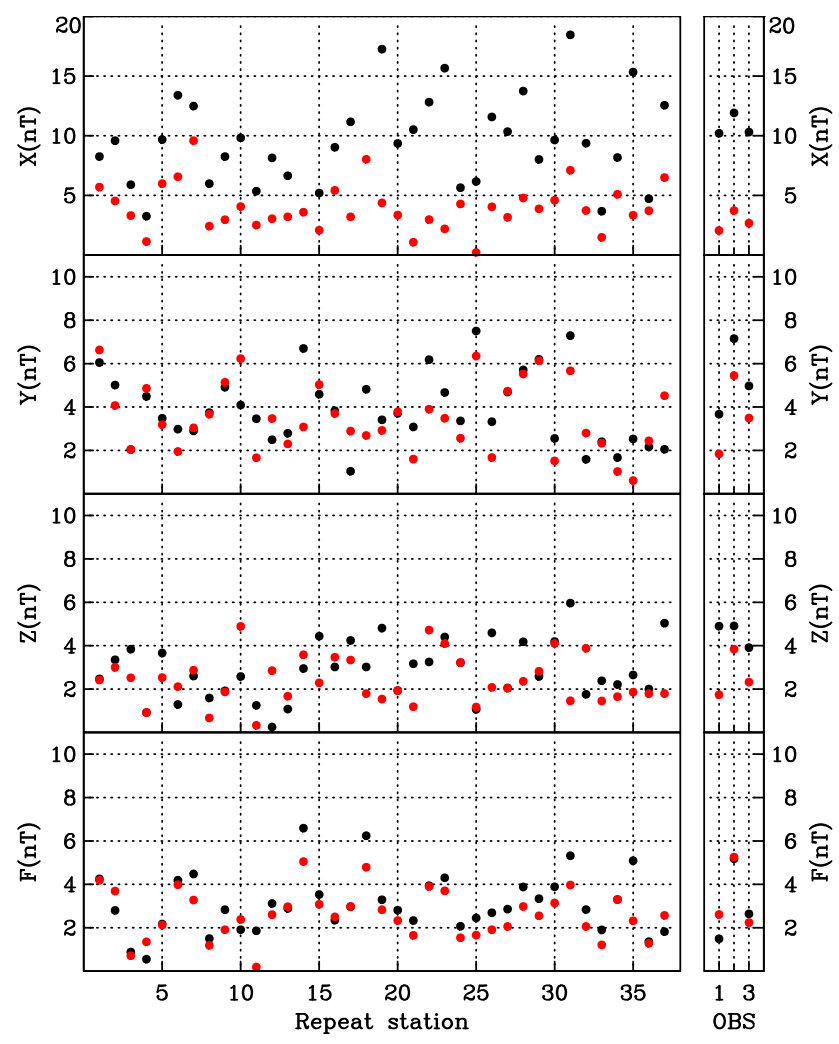

Figure 1. Standard deviation of individual repeat station (left) and observatory (right) lithospheric anomaly estimates around the mean value for southern Africa when only core field model values (black) or core and magnetospheric field model values (red) have been subtracted. In a few cases, the difference is so small that the black dot is hidden behind the red one.

erage values, representing the lithospheric estimate. Table 2 lists the average values of these offsets, and supplemental Fig. S1 shows their homogeneity with only a slight latitudinal dependence in $Z$ and $F$ components for the southern African region. Table 3 lists our final lithospheric anomaly estimates including the magnetospheric correction for the southern African repeat stations and observatories. 

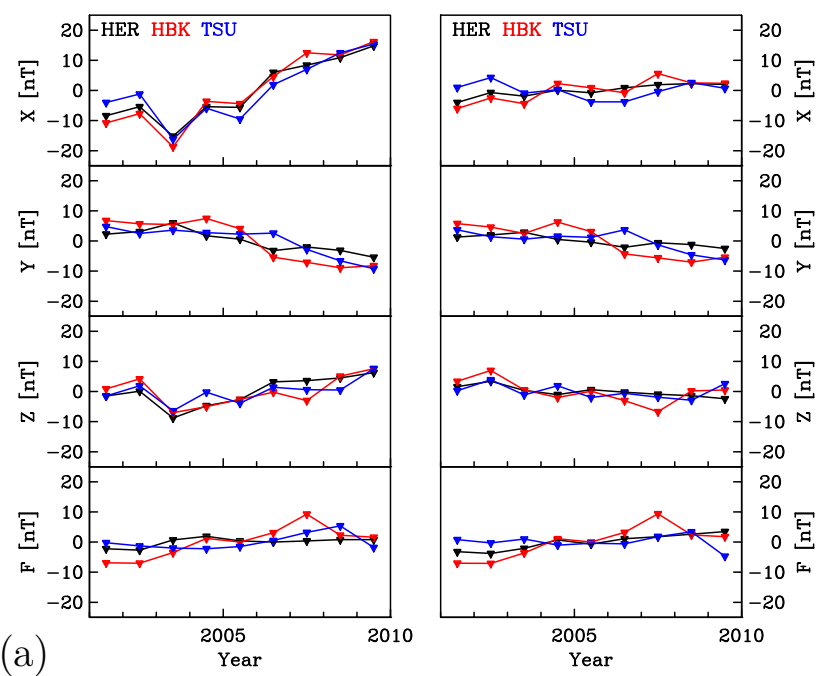

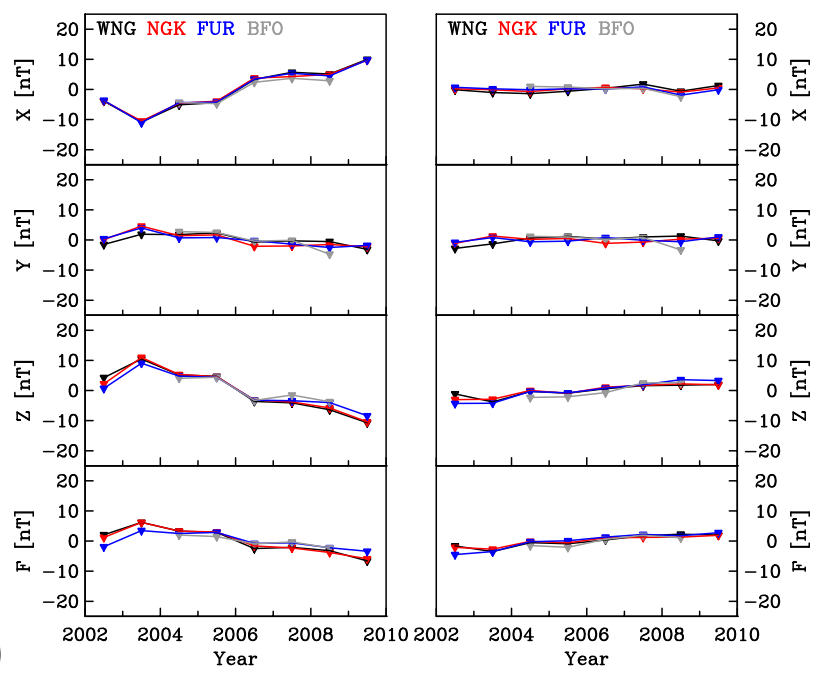

16)

Figure 2. Residuals of (a) southern African and (b) German observatory annual mean values after subtraction of GRIMM3 core field predictions (left panels) and core plus magnetospheric field estimates (right panels). Constant average values, representing the estimated lithospheric anomaly values, have been subtracted.

Table 2. Average magnetospheric offsets in lithospheric field estimates.

\begin{tabular}{lrrr}
\hline Component & $\begin{array}{r}\text { Southern Africa } \\
\text { RSs }(\sim \text { 5 years })\end{array}$ & $\begin{array}{r}\text { Southern Africa } \\
\text { OBSs }(\sim \text { 10 years })\end{array}$ & $\begin{array}{r}\text { Germany } \\
(8-10 \text { years })\end{array}$ \\
\hline$X(\mathrm{nT})$ & 11.6 & 21.1 & 14.2 \\
$Y(\mathrm{nT})$ & -1.8 & -3.7 & -3.7 \\
$Z(\mathrm{nT})$ & 7.1 & 10.7 & -18.7 \\
$F(\mathrm{nT})$ & 1.2 & 0.0 & -11.6 \\
\hline The offsets between lithospheric field estimates when only the core and when both core and \\
magnetospheric contribution are removed depend on time. The tabulated values are averaged \\
over all stations and, depending on data availability, in general 5 years for the southern \\
African repeat stations (RSs) and 10 years for the southern African observatories (OBSs) and \\
all German data.
\end{tabular}

\subsubsection{Germany}

In Germany, repeat station surveys on the whole network of 44 stations have been carried out biannually from 2004 to 2012, and on parts of the network between 1999 and 2003. In this case, the average spacing between stations is on the order of $150 \mathrm{~km}$. As the distances between the stations and observatories are much smaller than in southern Africa, a local variometer has only been set up at 12 stations, nevertheless for several nights. All measurements were first reduced to quiet night-time values (most quiet 2 to $4 \mathrm{~h}$ interval over the running period of the local variometer). The subsequent adjustment to annual means equivalents was done using Niemegk observatory recordings for all stations, which is justified twofold: (1) all measurements were done over the summer, close to the reduction epoch, and (2) the secular variation gradients over Germany are small (see Korte and Fredow, 2004, for details).

In this study we use data from 2003.5 to 2009.5 , including the annual means (averaged over all hours of the year) of the four German magnetic observatories Niemegk (NGK), Wingst (WNG), Fürstenfeldbruck (FUR), and Black Forest (BFO). Comparative annual means based on the GRIMM3 model predictions for core and core plus magnetospheric contributions are obtained as averages of predicted values for each hour of the year. Again, obvious outliers in the residual time series have been removed before averaging the residuals to obtain robust estimates of the lithospheric field contribution at each location. For 42 of the 44 repeat stations, robust results are obtained by averaging two to five (on average four) individual repeat station data. Individual results with their standard deviations are listed in supplementary Tables S5 and S6.

A clear reduction in scatter is seen when the magnetospheric contribution is considered (Table 1). Average offsets due to magnetospheric contributions in the lithospheric field estimation for this region are included in Table 2 and shown in supplemental Fig. S1. The final lithospheric estimates for the German repeat stations and observatories are listed in Table 4 .

\subsubsection{The magnetospheric field residual in different regions}

A comparison of the results from these two regions, located in the southern and northern hemispheres, at latitudes around $25^{\circ} \mathrm{S}$ and $51^{\circ} \mathrm{N}$, shows a similar and rather strong influence of multi-annual magnetospheric field signal in $X$, clearly latitude-dependent influence of opposite sign in $Z$, and nearly negligible influence in $Y$, as expected when the dominant (but not only) source is a ring current at large distance from the Earth. The differences obtained from annual 
Table 3. Observatory and repeat station lithospheric anomaly values for the southern African region with magnetospheric correction.

\begin{tabular}{|c|c|c|c|c|c|c|c|c|}
\hline Latitude & Longitude & Altitude (m) & $X(\mathrm{nT})$ & $Y(\mathrm{nT})$ & $Z(\mathrm{nT})$ & $F(\mathrm{nT})$ & No. of data* & Code \\
\hline-34.42 & 19.23 & 26.0 & 25.33 & 9.40 & 32.91 & -21.99 & 9 & HER \\
\hline-25.83 & 27.70 & 1522.0 & 90.31 & -28.86 & 54.06 & -5.66 & 9 & HBK \\
\hline-19.20 & 17.58 & 83.0 & 42.79 & -49.76 & 99.24 & -62.52 & 9 & TSU \\
\hline-34.02 & 24.78 & 210.0 & 5.62 & -18.69 & 70.07 & -57.68 & 4 & hum \\
\hline-34.02 & 22.38 & 180.0 & -31.39 & -94.07 & 14.23 & -7.67 & 4 & geo \\
\hline-32.93 & 28.03 & 20.0 & -53.94 & -31.56 & 109.07 & -112.74 & 4 & gon \\
\hline-32.78 & 20.53 & 754.0 & 45.43 & -48.64 & -88.92 & 106.12 & 3 & kar \\
\hline-32.17 & 25.63 & 847.0 & 75.51 & -28.19 & -69.89 & 97.61 & 5 & cra \\
\hline-31.35 & 20.93 & 1080.0 & -27.57 & -8.78 & -77.01 & 61.26 & 5 & wil \\
\hline-30.95 & 23.15 & 1065.0 & -108.27 & -133.39 & 66.82 & -80.46 & 4 & fon \\
\hline-30.60 & 17.98 & 229.0 & 2.03 & 73.95 & 50.35 & -56.09 & 5 & gar \\
\hline-30.05 & 19.47 & 900.0 & 114.40 & -136.02 & 146.71 & -70.66 & 4 & blo \\
\hline-29.78 & 29.48 & 1530.0 & -137.31 & -106.31 & 6.46 & -42.67 & 4 & und \\
\hline-29.22 & 27.47 & 1900.0 & -1.52 & -59.06 & 123.75 & -102.19 & 2 & lad \\
\hline-29.10 & 23.73 & 915.0 & -39.90 & 7.23 & 53.56 & -65.24 & 4 & dou \\
\hline-28.57 & 16.52 & 3.0 & 72.91 & -156.01 & 20.73 & 29.49 & 4 & ale \\
\hline-28.42 & 21.30 & 748.0 & 185.77 & 182.96 & -285.94 & 308.91 & 2 & upi \\
\hline-28.35 & 32.43 & 20.0 & -110.76 & 86.13 & 24.24 & -83.78 & 3 & stl \\
\hline-27.08 & 30.88 & 1246.0 & -77.43 & -44.89 & 128.23 & -139.91 & 5 & pie \\
\hline-26.62 & 15.18 & 20.0 & 101.51 & -11.64 & -175.59 & 201.02 & 4 & lud \\
\hline-26.58 & 22.85 & 890.0 & 198.36 & 154.95 & -67.08 & 122.58 & 5 & sev \\
\hline-24.73 & 15.35 & 587.0 & 0.22 & 64.74 & 165.87 & -157.93 & 5 & sos \\
\hline-24.72 & 19.88 & 1042.0 & -19.03 & -139.13 & -14.27 & 20.78 & 5 & uni \\
\hline-24.17 & 30.83 & 488.0 & 95.00 & -75.13 & 206.18 & -127.36 & 2 & mic \\
\hline-24.02 & 21.87 & 1068.0 & -2.93 & -144.81 & -185.18 & 181.21 & 5 & tsh \\
\hline-23.33 & 24.50 & 1000.0 & 17.23 & -53.00 & -269.04 & 252.95 & 5 & khu \\
\hline-23.07 & 28.00 & 900.0 & -167.39 & -325.17 & -592.02 & 485.18 & 5 & tom \\
\hline-22.67 & 14.57 & 30.0 & 158.62 & 145.69 & -65.57 & 111.46 & 2 & swa \\
\hline-22.57 & 17.10 & 1755.0 & -29.54 & 32.32 & -11.47 & -5.37 & 5 & win \\
\hline-22.50 & 18.97 & 1396.0 & -26.55 & 26.17 & 11.84 & -24.53 & 5 & gob \\
\hline-22.37 & 30.05 & 450.0 & 107.66 & -0.59 & 88.93 & -25.57 & 4 & mes \\
\hline-21.70 & 21.67 & 1093.0 & -11.19 & 9.12 & 83.43 & -79.97 & 5 & gha \\
\hline-21.27 & 25.32 & 904.0 & -23.10 & -4.40 & 61.98 & -64.89 & 4 & ora \\
\hline-21.17 & 27.50 & 1000.0 & 115.80 & -71.07 & 434.16 & -313.20 & 4 & fra \\
\hline-21.12 & 13.58 & 30.0 & 193.34 & -312.56 & -383.88 & 460.02 & 4 & uga \\
\hline-19.98 & 23.42 & 907.0 & 51.24 & 92.55 & -103.35 & 107.41 & 4 & mau \\
\hline-19.60 & 20.50 & 1100.0 & 63.67 & -75.70 & 26.12 & 13.83 & 3 & tsk \\
\hline-19.15 & 15.90 & 1039.0 & 1.09 & 26.28 & 84.28 & -75.57 & 4 & oka \\
\hline-17.63 & 24.18 & 950.0 & 92.12 & -23.49 & 81.32 & -18.80 & 3 & mpa \\
\hline-17.42 & 14.60 & 1112.0 & -23.82 & -121.44 & -25.86 & 21.03 & 4 & rua \\
\hline
\end{tabular}

* Number of data points used in time series.

means are more homogeneous than from individual nights, but depend on the length of the time series.

\subsection{Regional magnetic anomaly maps}

\subsubsection{High-resolution scalar anomalies}

For southern Africa, we consider the $1 \times 1 \mathrm{~km} \mathrm{SaNaBoZi}$ grid of scalar magnetic anomalies at $1 \mathrm{~km}$ altitude, encompassing South Africa, Namibia, Botswana, and Zimbabwe (M. Hamoudi, personal communication, 2014) as shown in Fig. 3a for the region of interest. This map is a combination of all available individual surveys which have been merged through resampling, interpolation, and upward continuation to produce a uniform map. The applied reprocessing methods are essentially those described by Hamoudi et al. (2007). Details on possible external field corrections applied to individual surveys are often unknown. In most cases, the influence of the fast external variations has likely been minimized by using magnetic data from a dedicated fixed base station or a nearby geomagnetic observatory. Anomaly values digitized from this grid at the locations of the southern African repeat stations are presented in supplemental Table S4. Note that 
Table 4. Observatory and repeat station lithospheric anomaly values for Germany with magnetospheric correction.

\begin{tabular}{|c|c|c|c|c|c|c|c|c|}
\hline Latitude & Longitude & Altitude (m) & $X(\mathrm{nT})$ & $Y(\mathrm{nT})$ & $Z(\mathrm{nT})$ & $F(\mathrm{nT})$ & No. of data* & Code \\
\hline 53.74 & 9.07 & 50.0 & 58.81 & 42.64 & -79.60 & -52.54 & 8 & WNG \\
\hline 52.07 & 12.68 & 78.0 & -16.83 & -2.76 & -88.32 & -88.16 & 8 & NGK \\
\hline 48.33 & 8.32 & 641.0 & 11.92 & -30.26 & 7.11 & 11.73 & 5 & $\mathrm{BFO}$ \\
\hline 48.16 & 11.28 & 572.0 & -10.44 & -9.30 & 2.70 & -2.27 & 8 & FUR \\
\hline 55.04 & 8.42 & 11.0 & 114.34 & -99.08 & 108.91 & 141.77 & 3 & lis \\
\hline 54.64 & 9.92 & 56.0 & 20.66 & 85.45 & -27.82 & -17.95 & 2 & eis \\
\hline 54.61 & 13.32 & 14.0 & 107.67 & 48.19 & 98.26 & 130.68 & 3 & alt \\
\hline 54.47 & 11.23 & 10.0 & -5.13 & -36.44 & -54.21 & -52.83 & 5 & ban \\
\hline 54.31 & 12.85 & 10.0 & 48.44 & -23.38 & -116.96 & -92.24 & 5 & kan \\
\hline 54.19 & 7.92 & 2.0 & 113.19 & -46.58 & 13.18 & 53.14 & 2 & hel \\
\hline 53.96 & 13.73 & 24.0 & 83.48 & 77.82 & 64.06 & 90.99 & 2 & bug \\
\hline 53.90 & 12.06 & 30.0 & 21.88 & -63.43 & -93.55 & -79.98 & 5 & kam \\
\hline 53.74 & 11.15 & 58.0 & 84.67 & -5.66 & 131.61 & 153.36 & 2 & bot \\
\hline 53.60 & 6.74 & 2.0 & 2.70 & 22.86 & -20.25 & -17.72 & 3 & bor \\
\hline 53.54 & 14.15 & 10.0 & 118.87 & 27.53 & -138.68 & -84.93 & 4 & kob \\
\hline 53.35 & 11.14 & 13.0 & 82.45 & -30.34 & -55.52 & -21.38 & 4 & goe \\
\hline 53.15 & 13.34 & 62.0 & 31.96 & -22.17 & -132.76 & -111.81 & 4 & $\tan$ \\
\hline 53.03 & 12.11 & 65.0 & 65.15 & 27.80 & 132.65 & 147.75 & 4 & hop \\
\hline 52.62 & 6.84 & 15.0 & -11.77 & 23.77 & -70.04 & -69.15 & 3 & eml \\
\hline 52.56 & 11.20 & 70.0 & 1.68 & -35.88 & -79.32 & -73.29 & 2 & jeg \\
\hline 52.49 & 14.37 & 50.0 & -10.03 & 6.89 & -82.86 & -80.51 & 4 & lie \\
\hline 52.02 & 7.86 & 60.0 & 37.45 & 12.52 & -43.19 & -25.25 & 3 & tel \\
\hline 51.88 & 11.44 & 140.0 & -21.26 & 5.29 & -64.74 & -67.84 & 3 & sch \\
\hline 51.83 & 6.07 & 12.0 & 5.80 & 7.65 & -69.87 & -62.06 & 3 & kee \\
\hline 51.79 & 10.35 & 601.0 & -10.22 & 14.11 & -61.86 & -60.82 & 3 & cla \\
\hline 51.53 & 10.05 & 289.0 & -24.35 & 19.92 & -71.30 & -74.89 & 4 & gtt \\
\hline 51.30 & 13.02 & 200.0 & -161.88 & 52.36 & -31.80 & -91.85 & 4 & col \\
\hline 51.28 & 14.16 & 160.0 & -74.22 & -65.09 & -11.93 & -41.21 & 4 & deu \\
\hline 51.17 & 11.63 & 290.0 & 58.34 & -41.05 & -22.29 & 2.28 & 4 & die \\
\hline 51.10 & 9.64 & 334.0 & -14.09 & 0.21 & -72.42 & -72.08 & 3 & eub \\
\hline 50.70 & 10.44 & 460.0 & 0.73 & 18.97 & 125.59 & 115.46 & 4 & gru \\
\hline 50.57 & 9.55 & 690.0 & -21.58 & 21.11 & -32.81 & -38.63 & 4 & obe \\
\hline 50.49 & 12.64 & 442.0 & -43.61 & -10.52 & -72.65 & -84.15 & 5 & sos \\
\hline 50.35 & 11.32 & 364.0 & -18.60 & -22.93 & -65.68 & -67.84 & 5 & eil \\
\hline 50.29 & 7.99 & 575.0 & -21.96 & -44.89 & -44.18 & -49.45 & 5 & ebe \\
\hline 50.25 & 6.31 & 580.0 & 32.35 & -90.11 & 16.88 & 28.72 & 5 & $\mathrm{rad}$ \\
\hline 49.92 & 12.39 & 309.0 & 16.27 & -8.75 & -56.36 & -44.80 & 5 & won \\
\hline 49.51 & 6.88 & 299.0 & 28.27 & -35.20 & -1.62 & 10.38 & 4 & nos \\
\hline 49.48 & 9.80 & 337.0 & 95.83 & -24.95 & 75.11 & 108.33 & 5 & mer \\
\hline 49.44 & 11.82 & 418.0 & -7.47 & -23.39 & -46.47 & -45.67 & 5 & gai \\
\hline 48.47 & 9.74 & 743.0 & -1.78 & 16.13 & 8.32 & 6.79 & 4 & ber \\
\hline 48.43 & 13.24 & 427.0 & -22.71 & -21.02 & -17.41 & -25.80 & 3 & poi \\
\hline 48.33 & 8.64 & 554.0 & -7.37 & -24.25 & -8.97 & -11.35 & 5 & wit \\
\hline 47.73 & 12.85 & 550.0 & -53.39 & 13.90 & 87.01 & 54.84 & 4 & kar \\
\hline 47.62 & 7.64 & 454.0 & 16.66 & -35.73 & 34.68 & 38.26 & 4 & oet \\
\hline 47.58 & 9.69 & 493.0 & -12.71 & 11.92 & -41.17 & -42.04 & 2 & $\operatorname{lin}$ \\
\hline
\end{tabular}

* Number of data points used in time series.

the resolution of this map is variable as gaps in aeromagnetic coverage have been interpolated in the regions of Lesotho and about $30 \%$ of the Namibian territory (strips along much of its northern border, the southern half of its western border, and an area in its southeast). Digitized values from high- resolution areas where strong anomaly gradients occur may have uncertainties up to a few tens of nT due to limited accuracy of the repeat station geographical coordinates. For Germany, a new high-resolution total field anomaly map has recently been compiled by Gabriel et al. (2011), based on 

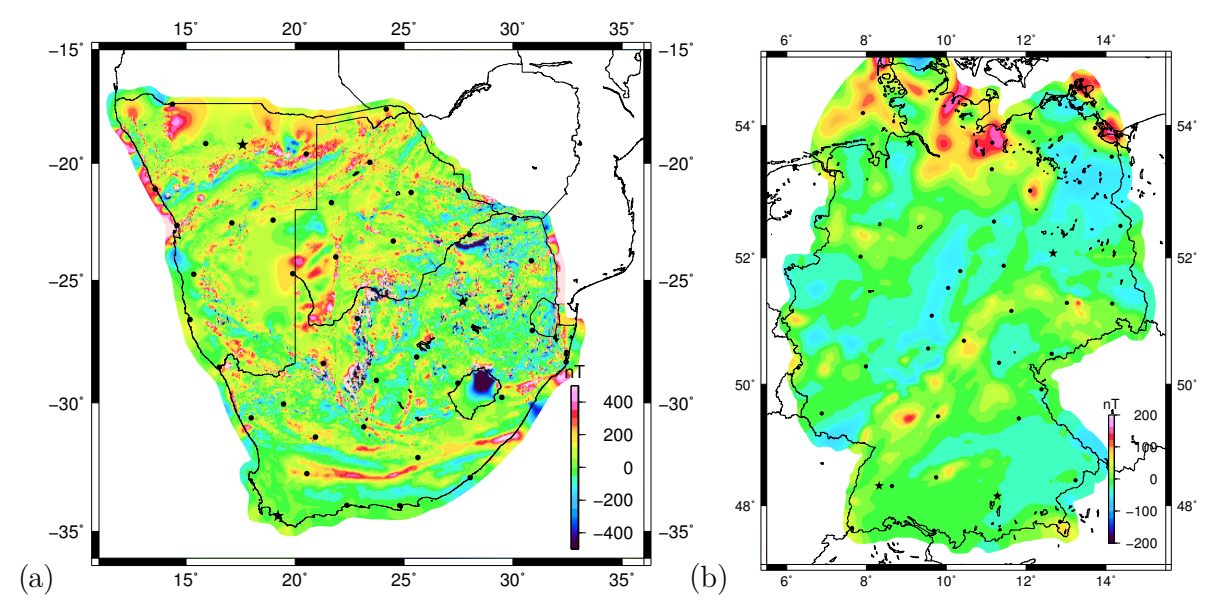

Figure 3. (a) SaNaBoZi grid (M. Hamoudi, personal communication, 2014) scalar field anomalies over the southern African region and (b) scalar field $5 \times 5 \mathrm{~km}$ grid anomaly map by Gabriel et al. (2011) for Germany, both including the locations of the geomagnetic observatories (black stars) and repeat stations (black dots) used in this study. Note regional differences in resolution in the southern African map. Different colour scales are used to accommodate the notable distinction in the maximum intensities of anomalies between the two regions.

67 individual airborne, shipborne, and ground surveys, processed earlier. The influence of the external field is that from the original processing of the surveys. Gabriel et al. (2011) reduced all surveys to the epoch 1980 by applying a secular variation correction to each one and then employed the DGRF 1980 (Definitive Geomagnetic Reference Field, see e.g. Thébault et al., 2015) to subtract the core field contribution. A uniform grid of $100 \mathrm{~m}$ spacing at $1000 \mathrm{~m}$ altitude above mean sea level was obtained by further adjusting and carefully combining the resulting surveys. A $5 \times 5 \mathrm{~km}$ grid of the map at $5 \mathrm{~km}$ altitude is freely available (see Fig. 3b). Intensity anomaly values at the German repeat station locations from the denser grid were provided by G. Gabriel (personal communication, 2015) and are tabulated in Table S4.

\subsubsection{Medium-resolution vector anomalies}

A medium-resolution vector field anomaly model for the southern African region has been obtained recently by Vervelidou (2013). This model is based on the values from the EMAG2 grid (Maus et al., 2009), selected CHAMP vector and scalar satellite data, and lithospheric vector field estimates from the observatories and the southern Africa repeat stations between 2005 and 2009 (reduced to annual means and with core field estimates from a previously determined regional model removed). The model has been obtained by the regional modelling method of revised spherical cap harmonic analysis (R-SCHA) and has a spatial resolution of approximately $60 \mathrm{~km}$. Maps derived from this model, showing the $X, Y$, and $Z$ component spatial distribution, are included in Fig. 4.

A similar R-SCHA-based model for Germany has been built by Korte and Thébault (2007), combining an aeromagnetic total field intensity compilation (Wonik et al., 2001), selected CHAMP vector and scalar satellite data, and vector crustal bias values from 48 German repeat stations and three geomagnetic observatories after subtraction of core field estimates. This model has a spatial resolution of approximately $37 \mathrm{~km}$ and the obtained maps are included in Fig. 5.

\subsection{Global anomaly maps}

\subsubsection{Vector magnetic anomalies}

The EMM2010 model $^{3}$ derived by Maus et al. (2010) describes the main and lithospheric magnetic field up to spherical harmonic degree and order 720 , equivalent to $56 \mathrm{~km}$ wavelength. The core field is computed from the spherical harmonic degrees 1 to 15 of the POMME-7 model based on selected CHAMP and Ørsted satellite data (an update of POMME- $6^{4}$ (Maus et al., 2010). The lithospheric part (NGDC-720) was obtained by an ellipsoidal harmonic representation of the total intensity EMAG2 grid (Maus et al., 2009) resampled by averaging in 15 arc min cells. The vector field can be reconstructed purely from intensity measurements except for a non-uniqueness resulting from the Backus effect (Backus, 1970). Maus et al. (2010) indicate that the local magnetic anomaly contributions perpendicular to the main field are therefore undetectable. The EMM2010 model is designed to describe the magnetic potential which explains the total intensity anomalies, while minimizing any perpendicular contributions undetectable in the scalar data (Maus et al., 2010). We explore the EMM2010 vector anomaly maps and values at the repeat station locations for truncation at spherical harmonic degree 720 ( $56 \mathrm{~km}$ wavelength) and, for later comparison to a recent gravity anomaly model, at degree 200 ( $\sim 200 \mathrm{~km}$ wavelength).

\footnotetext{
${ }^{3}$ https://www.ngdc.noaa.gov/geomag/EMM/emm2010.shtml

${ }^{4}$ http://geomag.org/models/pomme7.html
} 

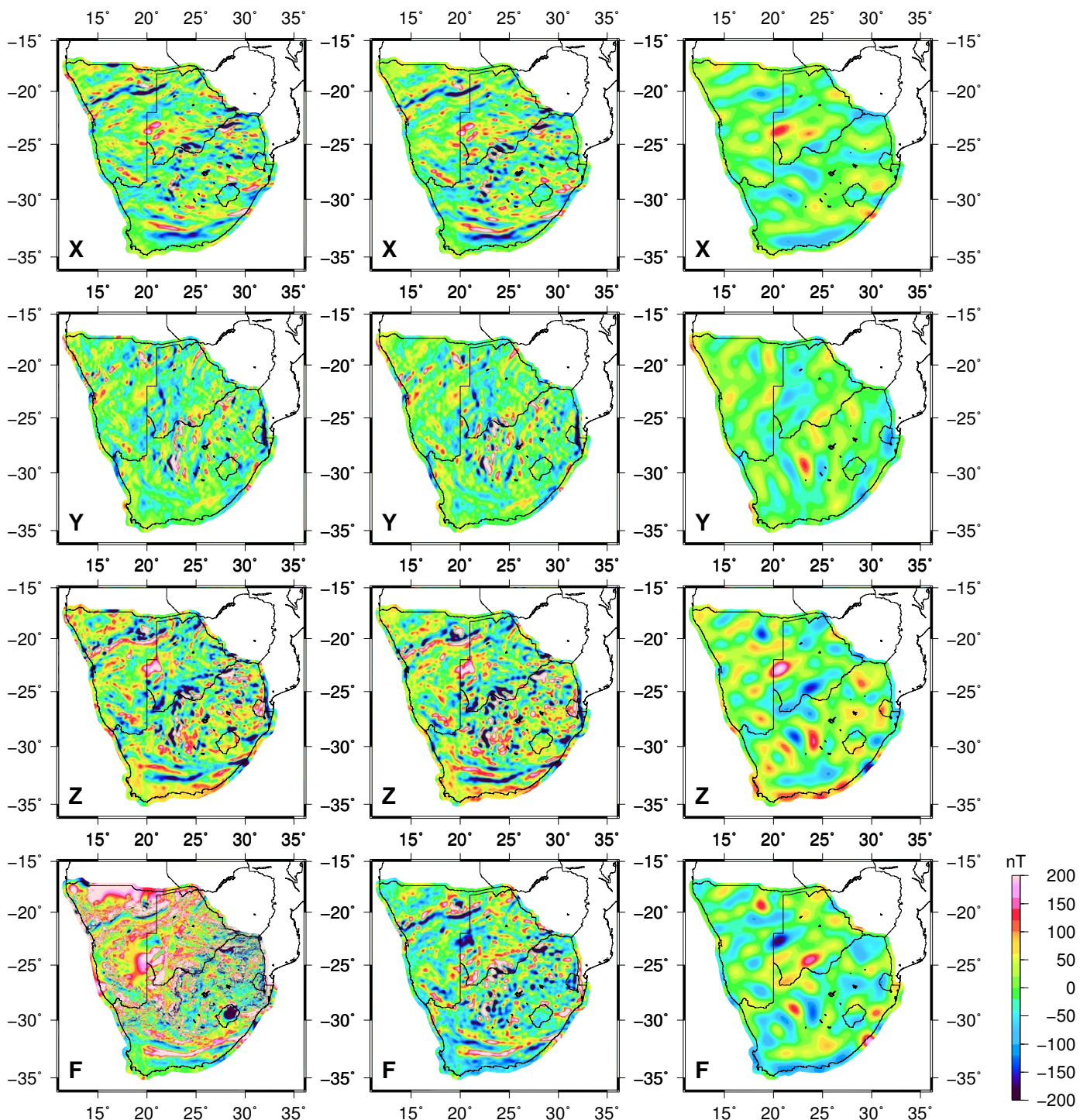

Figure 4. Different lithospheric field maps for southern Africa: regional R-SCHA model (orthogonal components) by Vervelidou (2013) and scalar high-resolution grid (M. Hamoudi, personal communication, 2014) as described in text and shown in Fig. 3a (left), global EMM2010 model of full (spherical harmonic (SH) degrees 15-720) resolution (middle) and truncated (SH degrees 15-200) EMM2010 (right). North $(X)$, east $(Y)$, vertical $(Z)$ anomaly components and scalar total field $(F)$ anomaly from top to bottom. All maps are on the same colour scale.

At spherical harmonic degrees around 13 to 16, the shortest observable wavelengths of the core field and longwavelength lithospheric field are of similar strength and it is impossible to clearly separate them. We found that the core field truncation to spherical harmonic degrees between 13 and 16 makes differences up to $5 \mathrm{nT}$ on resulting lithospheric anomaly estimates from the model. We then decided to consider the core field as representative up to spherical harmonic degree 14 and use degrees 15 and higher for the lithospheric field estimates.

Note that meanwhile, a newer version of the model, EMM2015, has been published (Chulliat et al., 2015). An unsystematic check indicates that utilization of the updated version does not change our results or conclusions.

\subsubsection{Gravity gradient anomalies}

Finally, we also take advantage of the new available gravity satellite information. The GOCE_DIR5 model released in 2014 is one of the official ESA (European Space Agency) gravity field models related to the GOCE $^{5}$ (Gravity field and steady-state Ocean Circulation Explorer) satellite mission (Bruinsma et al., 2014). The inverse model is expanded

\footnotetext{
${ }^{5}$ http://www.esa.int/Our_Activities/Observing_the_Earth/ GOCE/Satellite
} 

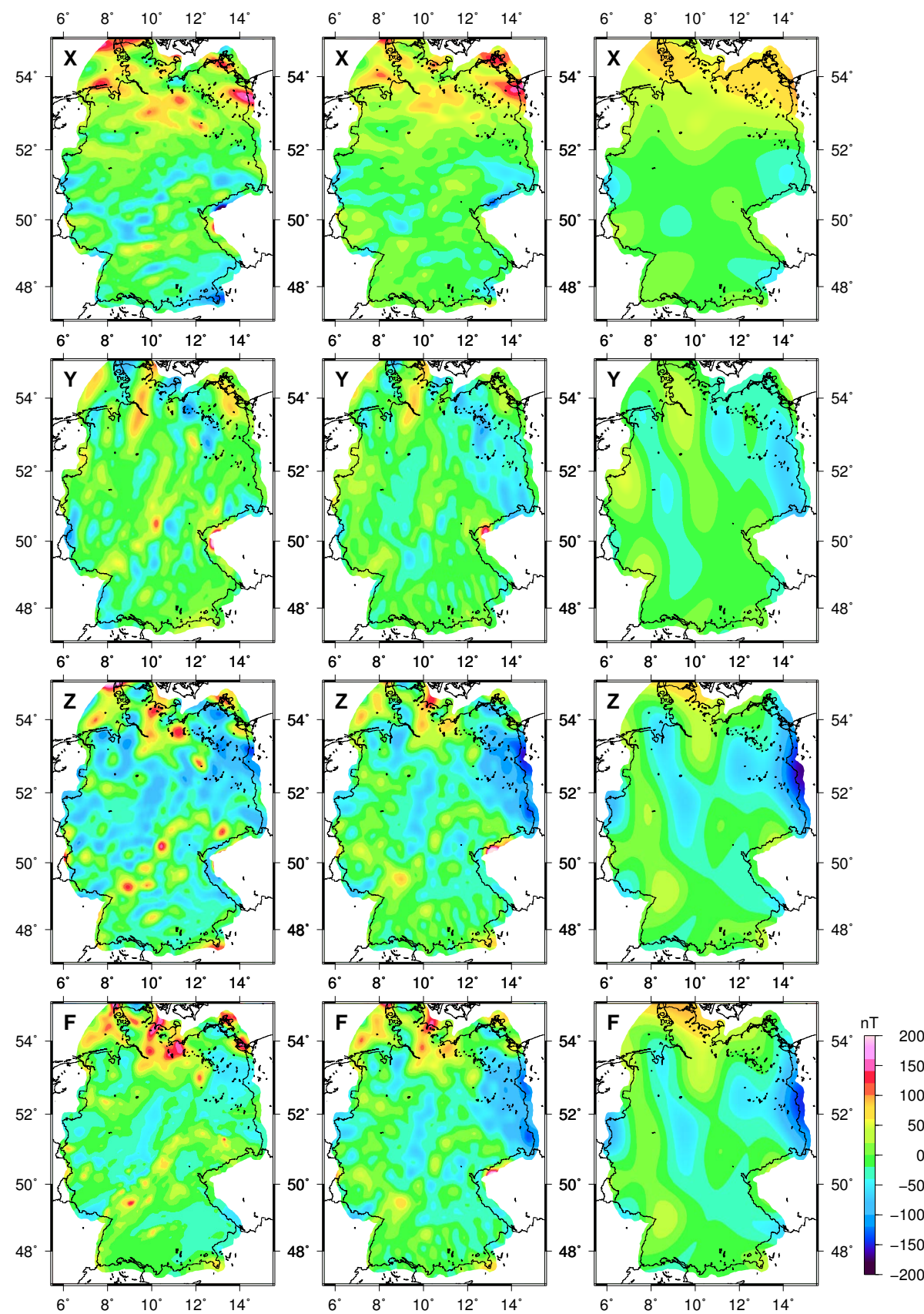

Figure 5. Different lithospheric field maps for Germany: regional R-SCHA model (orthogonal components) by Korte and Thébault (2007) and scalar grid by Gabriel et al. (2011) (left), global EMM2010 model of full (SH degrees 15-720) resolution (middle) and truncated (SH degrees 15-200) EMM2010 (right). North $(X)$, east $(Y)$, vertical $(Z)$ anomaly components and scalar total field $(F)$ anomaly from top to bottom. All maps are on the same colour scale.

to spherical harmonic degree and order 300 , but it is considered, by Bruinsma et al. (2014) themselves, to be most reliable up to degree and order 200 , beyond which the small scales might be influenced by noise. The gravity gradients in north $(d Y Y)$, east $(d X X)$, and vertical down $(d Z Z)$ direction up to degree and order 200 for the southern African region and Germany are shown in Figs. 8 and 9.
Gravity gradients are more sensitive to the high frequency potential of gravity than gravity data themselves because of their faster mitigation. Therefore, they have greater precision than gravity data for short wavelengths, and gravity maps made from gradiometer data have a higher resolution than those obtained from gravity data. In addition, the gradiometer data contain directional information, because they are ex- 
pressed in an orthogonal coordinate system. Gravimetry data provide a very good characterization of the centre of sources and a better visibility of deep sources, down to several hundreds of kilometres below the surface. The gradient data, in turn, allow us to reach a better definition of the geometry of the sources closer to the surface, from a few to some tens of kilometres (e.g. van der Meijde et al., 2015). Consequently they are better suited for comparison to magnetic anomaly data where the depth of sources is limited by the Curie depth. GOCE-based gravity gradient models reflect subsurface density and its vertical and lateral variability.

\section{Results and discussions}

\subsection{Short- and long-wavelength magnetic anomalies}

A comparison of short- and long-wavelength anomalies can reveal insights into concordances or discordances between shallower and deeper structures. Short wavelength or small scale in the following refers to the highest available resolution scalar and vector anomalies as shown in the left two columns of Figs. 4 and 5, while long wavelength or large scale refers to dimensions of several $100 \mathrm{~km}$ as determined by spherical harmonic models of potential field anomaly data truncated at degree and order 200.

The regional and global lithospheric anomaly models (left and middle columns of Figs. 4 and 5) show very close visual agreement in all three orthogonal field components in both southern Africa and Germany. An exception is a dominance of positive scalar anomalies in the Namibian region in the high-resolution scalar anomaly map which is somewhat opposed to what is seen in the map from the global model. The reason in this case seems to be a combination of two effects: mainly the inadequate interpolation of data over areas with a poor coverage (see Sect. 2.2.1), and probably the effect of some differences in zero levels (core field) between the map and the model. A comparison of short- and long-wavelength anomalies as represented by the highest available resolution maps and the EMM2010 model truncated at degree/order 200 (middle and right columns of Figs. 4 and 5) mostly shows a general broad agreement of positive/negative anomaly patterns in the three components and total intensity, but a closer look reveals some differences in the two study areas.

In southern Africa (Fig. 4) the elongated east-west Beattie anomaly (see, e.g. Quesnel et al., 2009; Scheiber-Enslin et al., 2014, and references therein) is denoted by an area dominated by strongly positive total field or negative vertical magnetic anomalies in the south of the studied area. Belts of south-west- to north-east-striking anomalies in northern Namibia clearly appear in the long-wavelength maps of the $F$ and $Z$ components. Similar patterns are observed in both the short- and long-wavelength maps of the $X$ component. In the same area the $Y$ component anomalies are generally northsouth-oriented, and again show a broad agreement between patterns in the short- and long-wavelength maps. Comparing the anomaly values at the repeat station locations (supplemental Tables S3 and S4) we note that in many cases, particularly for strong anomalies, the higher resolution values have higher amplitudes than the long-wavelength ones. Nevertheless, there are several exceptions for different field components. Differences between short- and long-wavelength anomalies for all ground stations on average are on the order of $30 \mathrm{nT}$ (absolute), with individual cases reaching up to $200 \mathrm{nT}$. At some locations the anomalies show different sign in one or more components.

In Germany, the percentage of repeat station locations characterized by an opposite sign for short- and longwavelength anomalies is about the same as in southern Africa. Due to the usually smaller amplitude of the anomalies in this region, the absolute difference is on the order of $10 \mathrm{nT}$ with maxima hardly larger than $100 \mathrm{nT}$ (supplemental Tables S7 and S8). The comparison of short- and longwavelength anomalies (Fig. 5) in this region, however, shows some clearer differences. A belt of positive total and vertical magnetic field anomalies stretching south-west to northeast through the southern part of Germany is not reflected in the long-wavelength map. Many anomaly features in the $F, Z$, and $Y$ components in the central and northern part of Germany are striking SSW to NNE in the short-wavelength maps, but appear oriented more SSE to NNW in the longwavelength representation. Less concordance between shallower and deeper structures appears to exist here than in the southern African region. However, it is also possible that the global model does not resolve these structures correctly, as it is ambitious to obtain these wavelengths from satellite data, and they are not contained in aeromagnetic survey data. An overall dichotomy in the $X$ component of both the short- and long-wavelength anomalies, with mostly positive values in the north and negative ones in the south, is hard to interpret.

\subsection{Repeat station lithospheric estimates and vector anomaly maps}

In order to compare the localized lithospheric anomaly estimates from the repeat stations to the available anomaly maps, we plot the values from supplemental Tables S3, S4, S7, and S8 in Figs. 6 and 7. Measurements and model values have all been interpolated using the same algorithm and parameters, giving a distorted image of the anomalies. This facilitates a direct visual comparison of amplitudes and signs of the values at the different locations, but the patterns should not be interpreted in any way.

In southern Africa, most of the $F$ and $Z$ field anomaly values show the same sign for ground data estimates and the high-resolution maps from the global and regional vector field anomaly model. Many of the ground data have higher amplitudes than predicted in particular by the global model. Obviously many of the ground stations lie on strong smallscale anomalies that are not fully resolved at the scale of 


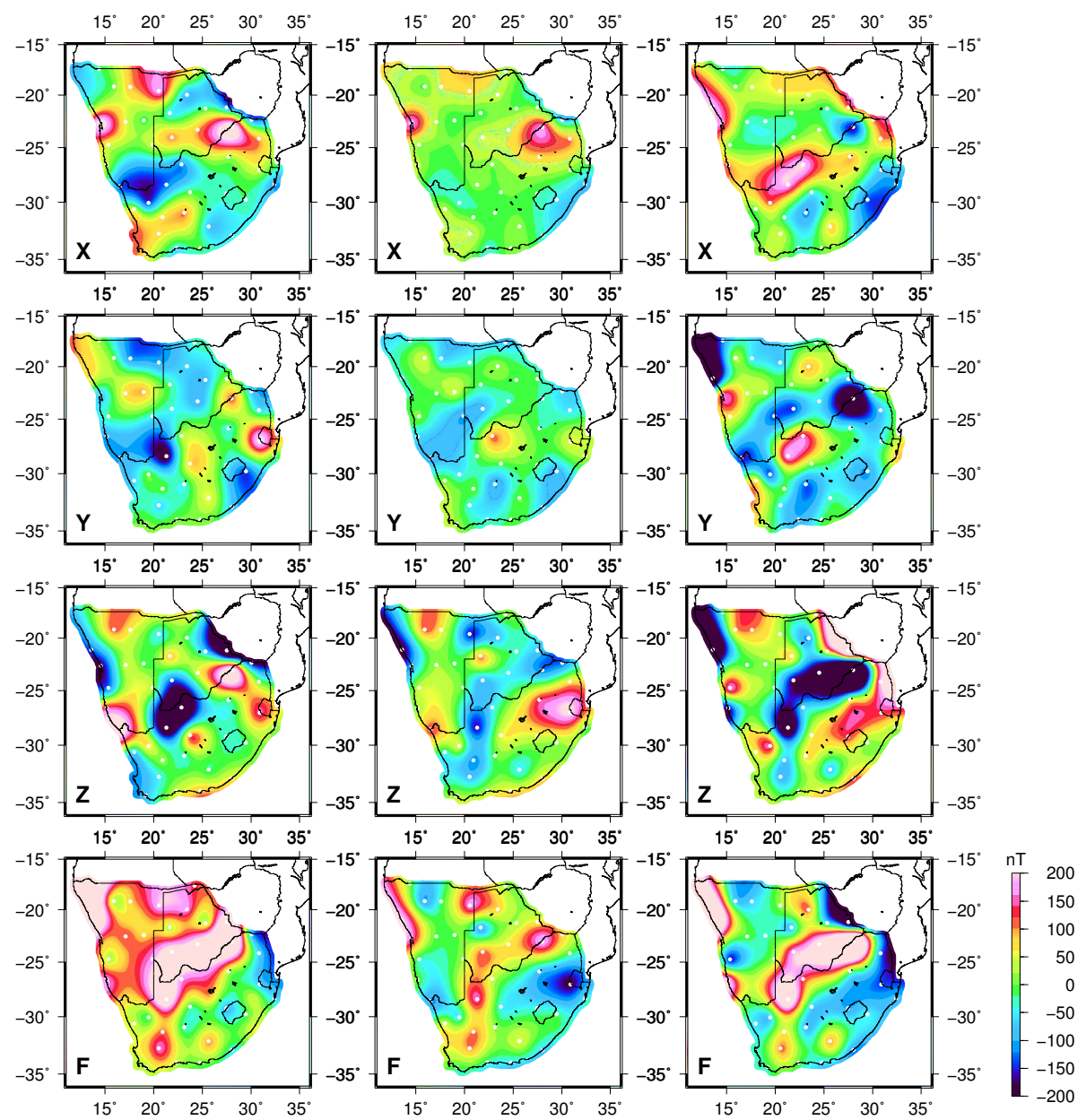

Figure 6. Estimates of lithospheric anomaly values at ground station locations, interpolated in the same way for a visual comparison (not reflecting the actual shape or dimension of anomalies). Orthogonal components based on the R-SCHA model and total field anomaly values from SaNaBoZi grid (left), predictions from EMM2010 model of SH degrees 15-720 (middle), and ground data processed as described in Sect. 2.1.1 (right). North $(X)$, east $(Y)$, vertical $(Z)$, and total field $(F)$ components from top to bottom and colour scale the same as in Fig. 4.

maps or within the known geographic accuracy of the repeat station locations. As noticed before, the scalar $F$ anomaly map tends to show more positive anomaly values in the Namibian region. More differences in relative amplitudes and signs are observed in the $Y$ and particularly $X$ components of the anomalies, where the global and regional maps seem to agree better with each other than with the ground measurements.

Similar results are obtained for Germany. Although the region is characterized by weaker anomalies, the amplitudes of $F$ and $Z$ field anomalies at the ground stations are once more generally higher than described by the EMM2010 model. The comparison to the highest resolution total anomaly map and the R-SCHA suggests that these differences might be due to a lack of resolution, as the repeat stations are placed on rather localized anomalies. In this case, the agreement for the two horizontal components $X$ and $Y$ of the anomalies is similar to that for $Z$ and $F$ component anomalies.

\subsection{Joint information from magnetic and gravity anomalies}

Small-scale magnetic anomalies are mostly due to nearsurface sources (some kilometres at most), while regional anomalies, in particular those seen from satellite altitude, are generally considered to originate from structures deeper in the lithosphere (km down to Curie depth) (Blakely, 1996). Differences in magnetization generally involve variations in the distribution, amount, and magnetic properties of magnetite in the lithosphere. Furthermore, the quantity of magnetite and its distribution is related to the composition and thickness of the lithosphere, while the magnetic properties are influenced by the temperature. The sources of regional anomalies can be diverse and their interpretation difficult. Combining magnetic and gravity gradient anomalies, the latter being related to density variations, provides complementary information in this regard. 

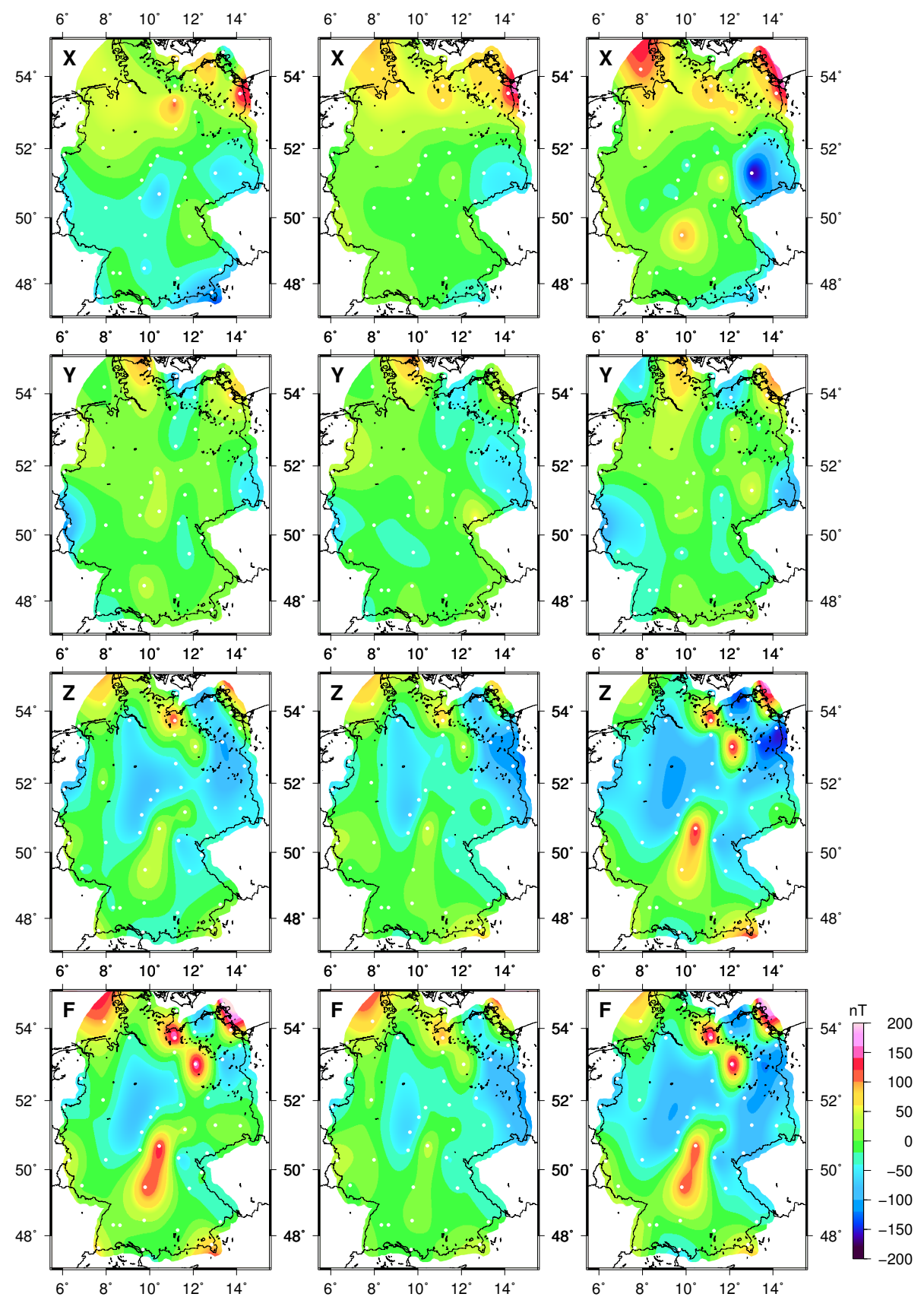

Figure 7. Estimates of lithospheric anomaly values at ground station locations, interpolated in the same way for a visual comparison (not reflecting the actual shape or dimension of anomalies). Orthogonal component estimates based on the R-SCHA model and total field anomaly values from the dense grid by Gabriel et al. (2011) (left), predictions from the EMM2010 model of SH degrees 15-720 (middle), and ground data processed as described in Sect. 2.1.2 (right). North $(X)$, east $(Y)$, vertical $(Z)$, and total field $(F)$ components from top to bottom and colour scale the same as in Fig. 5.

A detailed interpretation of the observed anomalies is beyond the scope of this study. In the following, we only discuss the relation between some prominent observed potential field anomalies and some large-scale tectonic features. Figures 8 and 9 show the long-wavelength magnetic and gravity gradient anomalies for the three orthogonal components north, east, and vertical down. A 2-D correlation of $5 \mathrm{~min}$ of arc grids of the magnetic and gravity gradient anomalies for the $Z$ component are also shown. We limit this correlation analysis to the vertical component, which is easier to interpret than the horizontal components. Large-scale tectonic structures are outlined and overlaid in these figures. For 


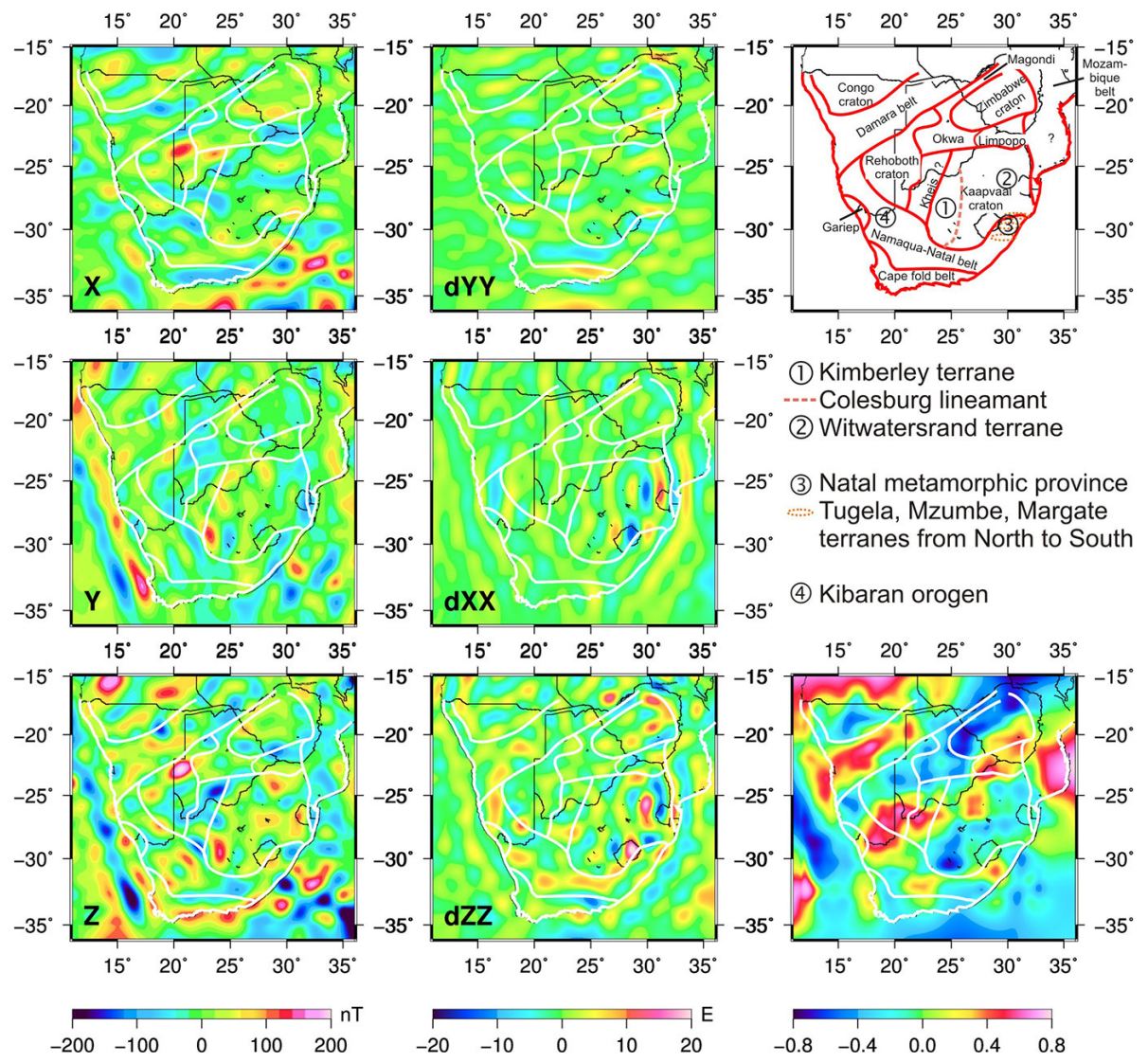

Figure 8. Comparison of long-wavelength magnetic and gravity anomalies for the southern African region. Left: lithospheric field from EMM2010 model of SH degrees 15-200 for north $(X)$, east $(Y)$, and vertical $(Z)$ components from top to bottom. Middle: gravity gradients in north $(d Y Y)$, east $(d X X)$, and vertical $(d Z Z)$ directions from top to bottom from GOCE-DIR5 model up to SH degree 200. Right: labelled outline of large-scale tectonic features (top) after Thomas et al. (1993) and Webb (2009) and correlation between vertical component magnetic and gravity anomalies (bottom).

southern Africa, this information is based on a combination of the maps by Thomas et al. (1993) and Webb (2009). For Germany, it is taken from the tectonics map by Berthelsen et al. (1992). Small-scale structures have all been omitted except for those specifically mentioned in the text.

\subsubsection{Southern Africa}

In the southern African region we observe similar strike directions in both magnetic and gravity gradient anomalies, with mainly east-west-oriented features in the north component anomalies, roughly north-south-oriented features in the east component, and more complicated, but comparable orientations in the vertical component (Fig. 8). At the investigated spatial wavelength, the potential field anomalies are clearly smaller than the large tectonic areas and direct links between anomaly patterns and these structures are not immediately obvious.

The Kaapvaal craton, consisting of granite-greenstone terranes and dated at 3.64-2.7 Ga, carries some of the strongest positive and negative gravity anomalies in the vertical and east component. The craton is supposed to consist of two halves: the older (3.7-3.1 Ga) eastern Witwatersrand terrane and the slightly younger $(<3.26 \mathrm{Ga})$, western Kimberly terrane, welded together along the Colesburg lineament (Webb, 2009 , and references therein). Indeed the western part is associated with stronger gravity gradient anomalies, and the Colesburg lineament, clearly seen in high-resolution aeromagnetic data (Webb, 2009, and Fig. 3), shows up as a weakly negative anomaly in the magnetic $Y$ and $Z$ components. The western edge of the Kaapvaal craton is not known well from previous work, as the Kheis and associated Proterozoic fold and thrust belts there are assumed to overlie the craton (e.g. Webb, 2009). Although the long-wavelength anomalies should primarily reflect deeper structures, we do not see any signal supporting a larger extension of the craton. In fact the Kheis and adjacent area is characterized by relatively strong negative magnetic vertical component anomalies that more likely are linked to the strong small-scale anomalies seen in high-resolution intensity anomaly maps (see Fig. 3). 

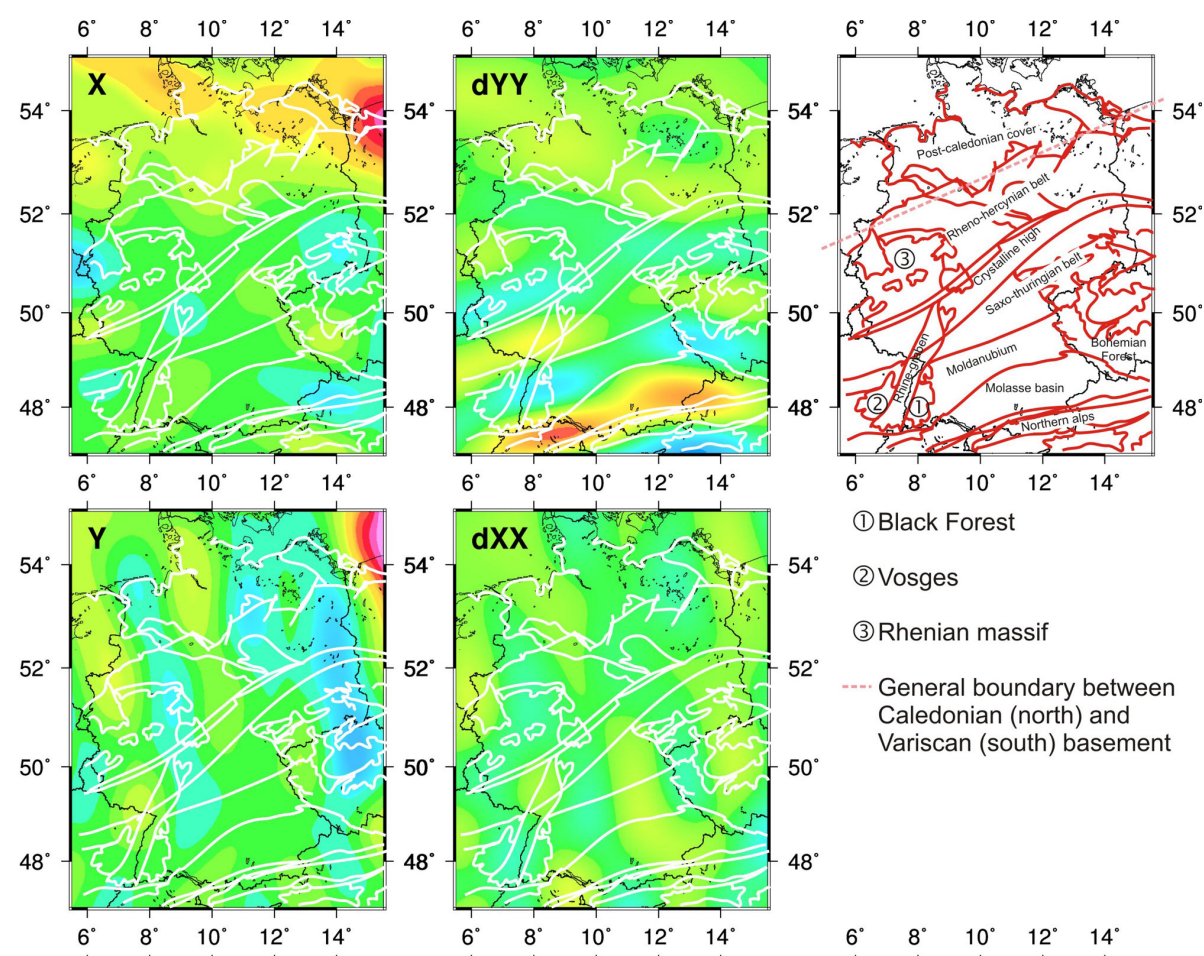

Black Forest

(2) Vosges

(3) Rhenian massif

-.- General boundary between Caledonian (north) and Variscan (south) basement
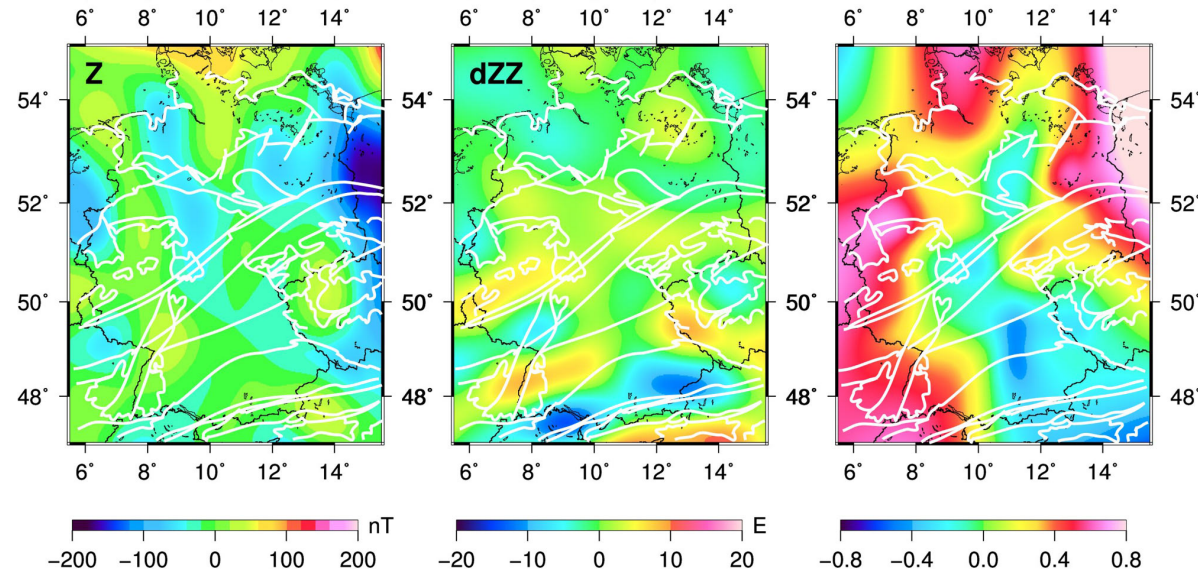

Figure 9. Comparison of long-wavelength magnetic and gravity anomalies for Germany. Left: lithospheric field from EMM2010 model of SH degrees 15-200 for north $(X)$, east $(Y)$, and vertical $(Z)$ components from top to bottom. Middle: gravity gradients in north $(d Y Y)$, east $(d X X)$, and vertical $(d Z Z)$ directions from top to bottom from GOCE-DIR5 model up to SH degree 200. Right: labelled outline of large-scale tectonic features (top) after Berthelsen et al. (1992) and correlation between vertical component magnetic and gravity anomalies (bottom).

The Namaqua-Natal Belt seems to be characterized by slightly positive vertical gravity gradient anomalies (Fig. 8). However, this belt of anomalies with possible continuation into the Damara belt and Kaapvaal craton also correlates well with topography and might reflect the isostatic roots of these structures. The Namaqua-Natal Belt is described as an area of higher heat flow (e.g. Webb, 2009), which would suggest Curie depths closer to the Earth's surface, and consequently fewer deep magnetic sources. This cannot be noticed in the wavelengths shown by our magnetic maps. The three terranes (Tugela, Mzumbe, and Margate, from north to south), which form the Natal Metamorphic Province at the easternmost end of the Namaqua-Natal Belt (e.g. Thomas et al., 1993;
Scheiber-Enslin et al., 2014) reflect in the $X$ and $Z$ component long-wavelength magnetic anomalies, as do structures of the Kibaran orogen, south-west of the Kheis area.

To the south, the Cape fold belt or its boundary with the Namaqua-Natal Belt is clearly visible as elongated E-Wstriking anomalies in several components in the magnetic and gravity gradient maps (Fig. 8). This area has been interpreted as a subduction zone corresponding to the prominent Beattie magnetic anomaly or as a cross-cutting panAfrican suture to the south of the Beattie anomaly (Thomas et al., 1993, and references therein). The $1000 \mathrm{~km}$ long Beattie Magnetic Anomaly is very well seen in aeromagnetic data but is less clear in the presented long-wavelength maps, al- 
though it has been suggested that the geological sources for this anomaly are mostly located in the middle crust (therefore the anomaly should be well represented by large wavelengths). It may be displaced by a shear zone or a fault (Quesnel et al., 2009). To explain this anomaly, some models suggested serpentinized relics of an inferred suture zone of the Natal-Namaqua Belt, others granulite-facies mid-crustal rocks within this belt (Quesnel et al., 2009). The latter explanation could be supported by the positive anomaly seen in the $d Z Z$ map, as serpentinite generally has lower density than granulite.

Another obvious link between tectonics and magnetic anomalies at this scale is seen along the western coast of South Africa and Namibia in all the components, which goes along with a similar structure of positive gravity $d Z Z$ anomalies (Fig. 8), indicating denser/deeper crust. This anomaly is ascribed to a volcanic province (Gaina et al., 2013), created by massive outpouring of basalt lavas during the break-up of the African and South American plates around $133 \mathrm{Ma}$ ago (Moulin et al., 2010).

The formal correlation between magnetic and gravity gradient anomalies in Fig. 8 shows several areas characterized by strong correlation, which is often positive, nonetheless sometimes negative as well. Despite the shorter wavelengths of the individual potential field anomalies, the correlations often are of the scale of the tectonic structures. As such, the southern part of the Congo craton in the north, as well as most of the Zimbabwe craton, the Okwa region, and the Kaapvaal craton, seem to be characterized by negative correlation, while areas of clearly positive correlations coincide well with the Damara and Limpopo belts. Another area of clear positive correlation over southern Namibia, southwestern Botswana, and small north-western parts of South Africa, however, crosses parts of three tectonic units.

\subsubsection{Germany and surroundings}

For the German region, Gabriel et al. (2011) found a partial reflection of supposed tectonic segments (see top right panel of Fig. 9) by the detailed aeromagnetic total intensity anomalies, which indeed can also be seen in the high-resolution component anomalies in Fig. 5. The northern German region of Caledonian crust overlain by Quaternary sediments (e.g. Berthelsen et al., 1992; Küster and Stöckhert, 2003) is characterized in this figure by rather long-wavelength total intensity magnetic anomalies with a mostly positive $X$ component. The whole area to the south of this, considered to lie on the Variscan basement (e.g. Berthelsen et al., 1992; Küster and Stöckhert, 2003), is characterized mainly by negative anomalies in all components. The exception here is the crystalline high, which is clearly reflected in a belt of positive total and vertical intensity anomalies in Fig. 5. However, there is no obvious agreement between the proposed tectonic units and the weak long-wavelength magnetic anomaly patterns shown in Fig. 9, possibly because their sizes are com- parable to the wavelength of the studied magnetic anomalies. The only exception is a stronger signature of the Caledonian than the Variscan basement in the $X$ component, supporting the interpretation by Gabriel et al. (2011) that the strong anomalies observed in the short-wavelength map are caused by deep-seated relicts of old Scandinavian crust below the sedimentary cover.

The gravity gradient anomalies on the same scale (Fig. 9), on the other hand, show some rather clear links: the Molasse basin in the south, where a sediment cover up to $4 \mathrm{~km}$ thick overlays the Variscan basement (e.g. Küster and Stöckhert, 2003 ), is characterized by negative $d Z Z$ and positive $d Y Y$ component anomalies. The mountain areas of the Bohemian Forest in the Czech Republic, the Black Forest and Vosges (France) around the southern Rhine Graben, and the Rhenian Massif on the west side of the Rheno-Hercynian Belt, all show positive $d Z Z$ and negative $d Y Y$ anomalies. Horizontal $d X X$ gravity gradient anomalies are weak over the whole region. Their strike directions and the long-wavelength $Y$ magnetic anomalies' strike directions are more similar than is the case for magnetic and gravity vertical components. Thus the $d X X$ gravity anomalies are less concordant than the other two components with proposed tectonic structures.

In contrast to results for the southern African area, the formal correlations between magnetic and gravity gradient anomalies in the vertical component (Fig. 9) are in this case hard to interpret. The only area well within the studied region that shows a somewhat significant positive correlation, is a patch in the south-eastern part of Germany that cannot be linked to any known tectonic structure. The amplitudes of the magnetic anomalies in this case are rather low. One question that cannot be answered at present is whether they are reliably resolved in the available model.

\subsubsection{Comparison of the two regions}

Higher visual and formal correlations among short- and longwavelength magnetic anomalies and gravity gradient data in southern Africa than in Germany might indicate higher concordance between shallower (few kilometres and less) and deeper (kilometres to tens of kilometres) structures in the former area. This interpretation agrees with differences in lithospheric thickness and heat flow in the two areas. McKenzie and Priestley (2008) estimated the lithospheric thickness from seismic shear wave velocities to lie mostly on the order of 100 to $220 \mathrm{~km}$ in the southern African region, with lowest values along the coasts and higher values dominating in the centre. In contrast, lithospheric thickness in Germany is given as less than $100 \mathrm{~km}$ everywhere by the same authors. Heat flow on the other hand is clearly lower in general in southern Africa. The global map of average heat flow presented by Shapiro and Ritzwoller (2004) gives values in the order of $50 \mathrm{~mW} \mathrm{~m}^{-2}$ in that region compared to about $80 \mathrm{~mW} \mathrm{~m}^{-2}$ in central Europe. Thin lithosphere with high heat flux should result in shallower Curie depths and conse- 
quently few to no deep magnetic sources. A thick lithosphere in combination with a low heat flux is clearly favourable for deep magnetic sources. However, Vervelidou and Thébault (2015) found lower values of magnetic crustal thickness for the southern African region $(\sim 30 \mathrm{~km})$ than central Europe $(\sim 55 \mathrm{~km})$ in their global model based on regional spectral analysis of a predecessor lithospheric magnetic field model to EMM2010. The European value is comparable to depth to the bottom of magnetic sources (DBMS) estimates for Germany by Bansal et al. (2011), who used the (shortwavelength) intensity anomaly map by Gabriel et al. (2011) (Fig. 3b) with a modified centroid depth method and obtained DBMS values between 22 and $45 \mathrm{~km}$.

The global geopotential field models invoked in this study are individual estimates of the large-scale anomalies. In particular for the magnetic field, the present ESA Swarm satellite constellation ${ }^{6}$ which comprises two parallel-flying satellites at low altitude, will provide new data and lead to improved long-wavelength lithospheric magnetic field models. These should be used both to determine additional DBMS estimates for southern Africa and to investigate the largewavelength anomalies in central Europe in order to confirm or revise our findings, which at present seem somewhat incompatible with the recent Curie depths estimates by Vervelidou and Thébault (2015).

\section{Conclusions}

In this study, we have investigated and compared lithospheric magnetic anomaly estimates provided by various data sources, from ground stations to low-Earth orbiting satellites over two geologically different regions, southern Africa and Germany. This choice has been determined by our experience of measuring the magnetic field variation on repeat station networks in both regions over more than a decade. Moreover, these areas provide rather different geological and geomagnetic settings, with very old cratons and strong magnetic anomalies in southern Africa and less strongly magnetized younger crust in central Europe.

Time series from geomagnetic repeat stations, spanning 5 to 10 years, provide robust estimates of the localized anomalies (repeat station crustal biases). Many of the repeat stations lie on rather strong, small-scale anomalies, which should be taken into account when using repeat station observations for core field mapping and modelling. Moreover, a clear longterm magnetospheric influence is still present in these data series after standard data processing; this contribution also has to be taken into account in core field and particularly secular variation studies using repeat station data. Likewise, this time-varying background magnetospheric field is not removed in the standard processing of aeromagnetic anomaly

\footnotetext{
${ }^{6}$ http://www.esa.int/Our_Activities/Observing_the_Earth/ The_Living_Planet_Programme/Earth_Explorers/Swarm/ESA_s_ magnetic_field_mission_Swarm
}

data and might be one cause of discrepancy when merging anomaly maps obtained in different epochs.

The comparison of short- and long-wavelength anomalies revealed that the long wavelengths often display similar patterns but with subdued amplitudes. However, they can also show quite different patterns, strike directions of anomalies, and signs. Both magnetic anomalies and gravity gradients at large $(\sim 200 \mathrm{~km})$ spatial scales show some known tectonic units well while not indicating others. Generally speaking, we found a better agreement between shortand long-wavelength magnetic anomalies and links to longwavelength gravity gradient anomalies for the southern African than the German region. Formal correlation between long-wavelength magnetic and gravity anomalies seems to reflect several tectonic structures in the southern African region rather well, but is hard to interpret for the German region. One possible explanation is that shallower and deeper lithospheric structures might be more concordant in the former area. This result seems in accordance with a thicker lithosphere and a lower heat flux reported in the literature for the southern African region, assumed to lead to a greater depth to the bottom of the magnetic sources or Curie depth, which, however, was not found in recent global estimates of magnetic crustal thickness. It is possible that weak largescale anomalies, as dominating in the German region, might not be reliably resolved in the global model and then should not be considered significant for interpretation or correlation. Improved global lithospheric magnetic field models expected from ESA's Swarm satellite mission might solve these discrepancies in the near future.

Overall, our results indicate that the investigation of potential fields at different wavelengths can aid geological and tectonic mapping and interpretation, and the correlation results for southern Africa encourage modelling of large-scale tectonic units from joint magnetic and gravity anomaly longwavelength signals.

\section{Data availability}

No measurement data were obtained within the framework of this study. The data products used for our analyses are available as follows.

- The repeat station data are stored in the magnetic survey database of the World Data Centre for Geomagnetism, Edinburgh, at http://www.geomag.bgs.ac. uk/data_service/data/surveydata.shtml.

- High-resolution magnetic intensity anomaly maps may be of commercial value and some of the owners of the underlying data sets prohibit that such maps and in particular grid values be deposited in freely accessible repositories. We obtained both data sets, for southern Africa and Germany, by personal request from the authors M. Hamoudi (Hamoudi et al., 2007) and G. Gabriel (Gabriel et al., 2011). 
- The grid values from high-resolution vector magnetic anomaly models have been obtained by personal request from the authors of the respective publications: $\mathrm{F}$. Vervelidou for Southern Africa (Vervelidou, 2013), E. Thébault for Germany (Korte and Thébault, 2007).

- The vector magnetic anomaly grid values from the global EMM2010 model (Maus et al., 2010) have been obtained from model and software provided on the NOAA website https://www.ngdc.noaa.gov/ geomag/EMM/emm2010.shtml.

- The gravity gradient grid values from the GOCE_Dir5 model (Bruinsma et al., 2014) can be obtained interactively from the International Centre for Global Earth Models (ICGEM) website http://icgem.gfz-potsdam.de/ ICGEM/ICGEM.html.

Acknowledgements. We thank Gerald Gabriel for providing digital values from the high-resolution German scalar magnetic anomaly map at the repeat station locations, Mohammed Hamoudi for providing the southern African $\mathrm{SaNaBoZi}$ grid, and Foteini Vervelidou for providing predictions from her R-SCHA regional model. Georges Balmino and Olivier de Viron are thanked for providing grid values from the GOCE-DIR5 gravity model and providing grid correlations between magnetic and gravity data, respectively. The South African National Space Agency (SANSA), Space Sciences in Hermanus is acknowledged for providing the processed southern African repeat station data and for operating the Hermanus, Hartebeesthoek, and Tsumeb geomagnetic observatories. The University of Munich is acknowledged for operation of the Fürstenfeldbruck observatory, and the Universities of Stuttgart and Karlsruhe for the Black Forest observatory. Maps were created with the Generic Mapping Tools software, version 4, by Wessel and Smith (1998).

The article processing charges for this open-access publication were covered by a Research

Centre of the Helmholtz Association.

Edited by: A. Longo

\section{References}

Backus, G. E.: Non-uniqueness of the external geomagnetic field determined by surface intensity measurements, J. Geophys. Res., 75, 6339-6341, 1970.

Bansal, A. R., Gabriel, G., Dimri, V. P., and Krawczyk, C. M.: Estimation of depth to the bottom of magnetic sources by a modified centroid method for fractal distribution of sources: An application to aeromagnetic data in Germany, Geophysics, 76, L11-L22, 2011.

Barraclough, D. and De Santis, A.: Repeat Station Activities, in: Geomagnetic Observations and Models, 45-56, Springer, 2011.
Berthelsen, A., Burollet, P., Piaz, G. V. D., Franke, W., and Trümpy, R.: Tectonics, in: A Continent Revealed: The European Geotraverse, edited by: Blundell, D., Freeman, R., and Mueller, S., Cambridge University Press, 1992.

Blakely, R.: Potential Theory in Gravity \& Magnetic Applications, Cambridge University Press, 1996.

Bruinsma, S. L., Förste, C., Abrikosov, O., Lemoine, J.-M., Marty, J.-C., Mulet, S., Rio, M.-H., and Bonvalot, S.: ESA's satelliteonly gravity field model via the direct approach based on all GOCE data, Geophys. Res. Lett., 41, 7508-7514, 2014.

British Geological Survey: Magnetic Survey Data Form, http:// www.geomag.bgs.ac.uk/data_service/data/surveydata.shtml, last access: June 2014.

Chulliat, A., Alken, P., Nair, M., Woods, A., and Maus, S.: The Enhanced Magnetic Model 2015-2020, National Centers for Environmental Information, NOAA, doi:10.7289/V56971HV, last access: June 2015.

Dyment, J., Lesur, V., Hamoudi, M., Choi, Y., Thebault, E., Catalan, M., the WDMAM Task Force, the WDMAM Evaluators, and the WDMAM Data Providers: World Digital Magnetic Anomaly Map version 2.0, map available at: http://www.wdmam.org, 2015.

Gabriel, G., Vogel, D., Scheibe, R., Lindner, H., Pucher, R., Wonik, T., and Krawczyk, C. M.: Anomalies of the Earth's total magnetic field in Germany-the first complete homogenous data set reveals new opportunities for multiscale geoscientific studies, Geophys. J. Int., 184, 1113-1118, 2011.

Gaina, C., Torsvik, T. H., van Hinsbergen, D. J. J., Medvedev, S., Werner, S. C., and Labails, C.: The African Plate: A history of oceanic crust accretion and subduction since the Jurassic, Tectonophysics, 604, 4-25, 2013.

Hamoudi, M., Thébault, E., Lesur, V., and Mandea, M.: GeoForschungsZentrum Anomaly Magnetic Map (GAMMA): a candidate model for the World Digital Magnetic Anomaly Map, Geochem. Geophy. Geosy., 8, Q06023, doi:10.1029/2007GC001638, 2007.

Hamoudi, M., Quesnel, Y., Dyment, J., and Lesur, V.: Aeromagnetic and Marine Measurements, in: Geomagnetic Observations and Models, 57-103, Springer, 2011.

Korhonen, J. V., Fairhead, J. D., Hamoudi, M., Hemant, K., Lesur, V., Mandea, M., Maus, S., Purucker, M., Ravat, D., Sazonova, T., and Thébault, E.: Magnetic Anomaly Map of the World (and associated DVD), Scale: 1:50000 000, 1st edition, Commission for the Geological Map of the World, Paris, France, 2007.

Korte, M.: Long-term external field contributions in geomagnetic repeat station results, Journal of Indian Geophysical Union, Proceedings of the XVI IAGA Workshop on Geomagnetic Observatories Isntruments, Data Acquisition and Processing, 2015.

Korte, M. and Fredow, M.: Magnetic repeat station survey of Germany 1999/2000, Scientific Technical Report STR01/04, GeoForschungsZentrum Potsdam, 2004.

Korte, M. and Haak, V.: Modelling European magnetic repeat station and survey data by SCHA in search of time-varying anomalies, Physics of the Earth and Planetary Interiors, 122, 205-220, 2000.

Korte, M. and Thébault, E.: Geomagnetic repeat station crustal biases and vectorial anomaly maps for Germany, Geophys. J. Int., 170, 81-92, 2007. 
Korte, M., Mandea, M., Kotzé, P., Nahayo, E., and Pretorius, B.: Improved observations at the southern African geomagnetic repeat station network, S. Afr. J. Geol., 110, 175-186, 2007.

Küster, M. and Stöckhert, B.: Der tektonische Bau Deutschlands, in: Nationalatlas Bundesrepublik Deutschland - Relief, Boden und Wasser, edited by: Liedtke, H., Mäusbacher, R., and Schmidt, K.H., Leibnitz Institut für Länderkunde, Spektrum Akademischer Verlag, 2003.

Lesur, V., Wardinski, I., Hamoudi, M., and Rother, M.: The second generation of the GFZ Reference Internal Magnetic Model: GRIMM-2, Earth Planets Space, 62, 765-773, 2010.

Mandea, M., Panet, I., Lesur, V., de Viron, O., Diament, M., and Mouël, J.-L. L.: Recent changes of the Earthś core derived from satellite observations of magnetic and gravity fields, P. Natl. Acad. Sci. USA, 109, 19129-19133, 2012.

Maus, S., Yin, F., Lühr, H., Manoj, C., Rother, M., Rauberg, J., Michaelis, I., Stolle, C., and Müller, R. D.: Resolution of direction of oceanic magnetic lineations by the sixth-generation lithospheric magnetic field model from CHAMP satellite magnetic measurements, Geochem. Geophy. Geosy., 9, Q07021, doi:10.1029/2008GC001949, 2008.

Maus, S., Barckhausen, U., Berkenbosch, H., Bournas, N., Brozena, J., Childers, V., Dostaler, F., Fairhead, D., Finn, C., Freese, R. R. B. V., Gaina, C., Golynsky, S., Kucks, R., Lühr, H., Milligan, P., Mogren, S., Müller, R. D., Olesen, O., Pilkington, M., Saltus, R., Schreckenberger, B., Thébault, E., and Tontini, F. C.: EMAG2: A 2-arc min resolution Earth Magnetic Anomaly Grid compiled from satellite, airborne, and marine magnetic measurements, Geochem. Geophy. Geosy., 10, Q08005, doi:10.1029/2009GC002471, 2009.

Maus, S., Manoj, C., Rauberg, J., Michaelis, I., and Lühr, H.: NOAA/NGDC candidate models for the 11th generation International Geomagnetic Reference Field and the concurrent release of the 6th generation Pomme magnetic model, Earth Planets Space, 62, 729-735, 2010.

McKenzie, D. and Priestley, K.: The influence of lithospheric thickness variations on continental evolution, Lithos, 102, 1-11, 2008.

Moulin, M., Aslanian, D., and Unternehr, P.: A new starting point for the South and Equatorial Atlantic Ocean, Earth-Sci. Rev., 98, 1-37, 2010.

Newitt, L. R., Barton, C. E., and Bitterly, J.: Guide for magnetic repeat station surveys, International Association of Geomagnetism and Aeronomy, 1996.

Olsen, N. and Kotsiaros, S.: Magnetic satellite missions and data, in: Geomagnetic Observations and Models, 27-44, Springer, 2011.

Quesnel, Y., Weckmann, U., Ritter, O., Stankiewicz, J., Lesur, V., Mandea, M., Langlais, B., Sotin, C., and Galdéano, A.: Simple models for the beattie magnetic anomaly in South Africa, Tectonophysics, 478, 111-118, 2009.

Rajaram, M.: Depth to Curie Temperature, in: Encyclopedia of Geomagnetism and Paleomagnetism, 157-159, Springer, 2007.

Ravat, D. N., Hinze, W. J., and Frese, R. R. B. V.: Analysis of Magsat magnetic contrasts across Africa and South America, Tectonophysics, 212, 59-76, 1992.
Ravat, D. N., Hinze, W. J., and Taylor, P. T.: European tectonic features observed by Magsat, Tectonophysics, 220, 157-173, 1993.

Regan, R. D., Cain, J. C., and Davis, W. M.: A global magnetic anomaly map, J. Geophys. Res., 80, 794-802, 1975.

Scheiber-Enslin, S., Ebbing, J., and Webb, S. J.: An integrated geophysical study of the Beattie magnetic anomaly, South Africa, Tectonophysics, 636, 228-243, 2014.

Shapiro, N. M. and Ritzwoller, M. H.: Inferring surface heat flux distributions guided by a global seismic model: particular application to Antarctica, Earth Planet. Sc. Lett., 223, 213-224, 2004.

Thébault, E., Mandea, M., and Schott, J.: Modeling the lithospheric magnetic field over France by means of revised spherical cap harmonic analysis (R-SCHA), J. Geophys. Res, 111, B05102, doi:10.1029/2005JB004110, 2006.

Thébault, E., Hemant, K., Hulot, G., and Olsen, N.: On the geographical distribution of induced time-varying crustal magnetic fields, Geophys. Res. Lett., 36, L01307, doi:10.1029/2008GL036416, 2009.

Thébault, E., Finlay, C. C., Beggan, C., Alken, P., Aubert, J., Barrois, O., Bertrand, F., Bondar, T., Boness, A., Brocco, L., Canet, E., Chambodut, A., Chulliat, A., Coïsson, P., Civet, F., Du, A., Fournier, A., Fratter, I., Gillet, N., Hamilton, B., Hamoudi, M., Hulot, G., Jager, T., Korte, M., Kuang, W., Lalanne, X., Langlais, B., Léger, J. M., Lesur, V., Lowes, F. J., Macmillan, S., Mandea, M., Manoj, C., Maus, S., Olsen, N., Petrov, V., Rother, M., Sabaka, T. J., Saturnino, D., Schachtschneider, R., Sirol, O., Tangborn, A., Taylor, V., Thomson, A., Tøffner-Clausen, L., Vigneron, P., Wardinski, I., and Zvereva, T.: International Geomagentic Reference Field: the twelfth generation, Earth Planets Space, 67, doi:10.1186/s40623-015-0228-9, 2015.

Thomas, R. J., von Veh, M. W., and McCourt, S.: The tectonic evolution of southern Africa: and overview, J. African Earth Sci., 16, 5-24, 1993.

van der Meijde, M., Pail, R., Bingham, R., and Floberghagen, R.: GOCE data, models, and applications: A review, Int. J. Appl. Earth Obs., 35, 4-15, 2015.

Vervelidou, F.: Contribution à la modélisation et à l'interprétation multi-échelle du champ magnétique de la lithosphére terrestre, Ph.D. thesis, Université Paris Diderot, 2013.

Vervelidou, F. and Thébault, E.: Global maps of the magnetic thickness and magnetization of the Earthś lithosphere, Earth Planets Space, 67, 1-19, 2015.

Webb, S. J.: The use of potential field and seismological data to analyze the structure of the lithosphere beneath southern Africa, $\mathrm{Ph}$.D. thesis, School of Geosciences, University of the Witwatersrand, 2009.

Wessel, P. and Smith, W. H. F.: New, improved version of the Generic Mapping Tools released, Eos Trans. AGU, 79, p. 579, 1998.

Wonik, T., Trippler, K., Geipel, H., Greinwald, S., and Pashkevitch, I.: Magnetic anomaly map for Northern, Western, and Eastern Europe, Terra Nova, 13, 203-213, 2001. 